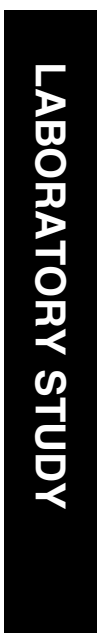

\title{
Phenotypic heterogeneity associated with a novel mutation (Gly112Glu) in the Norrie disease protein
}

${ }^{1}$ Molecular Ophthalmology Laboratory, Center for Macular Degeneration, The University of lowa Carver School of Medicine, lowa City, IA, USA

\section{${ }^{2}$ Department of}

Ophthalmology and Visual Sciences, The University of lowa Carver School of

Medicine, lowa City, IA, USA

\section{${ }^{3}$ Department of}

Ophthalmology Eye Hospital, University of Wuerzburg, Wuerzburg, Germany

Correspondence: SR Russell, Vitreoretinal Service, Department of Ophthalmology and Visual Sciences, The University of lowa Carver School of Medicine, 200 Hawkins Drive, lowa City, IA 52242, USA

Tel: + 13193564588

Fax: + 13193560363

E-mail: steve-russell@

uiowa.edu

Received: 4 August 2004 Accepted in revised form: 12 December 2004; Published onilne: 18 March 2005

\begin{abstract}
Purpose To determine the molecular pathology and clinical severity of two pedigrees with a history of early retinal detachment and peripheral retinal vascular abnormalities.

Design Longitudinal cohort study.

Methods A longitudinal clinical study and DNA analysis was performed on 49 family members of two pedigrees.

Results Nine individuals were found to be hemizygous for a mutation at codon $\mathbf{1 1 2}$ (Gly112Glu) of the Norrie disease protein (NDP) in one pedigree. Significant phenotypic heterogeneity was found. The proband presented with a unilateral subtotal retinal detachment at the age of 3 years, and subsequently developed a slowly progressive tractional retinal detachment involving the macula in the contralateral eye at the age of 4 years. One individual had only mild peripheral retinal pigmentary changes with normal vision at the age of 79 years. The remaining seven individuals had varying degrees of peripheral retinal vascular abnormalities and anterior segment findings. Seven affected members of a second pedigree affected by a previously reported mutation, Arg74Cys, also demonstrated wide ocular phenotypic variation.

Conclusion A novel mutation (Gly112Glu), which represents the most carboxy located, NDP mutation reported, results in significant phenotypic heterogeneity. These data support the contention that the spectrum of ocular disease severity associated with these NDP mutations is broad. Use of terms that characterize this entity by phenotypic
\end{abstract}

RC Allen ${ }^{1,2}$, SR Russell ${ }^{1,2}$, LM Streb ${ }^{1,2}$, A Alsheikheh ${ }^{3}$ and EM Stone ${ }^{1,2}$ appearance, such as familial exudative vitreoretinopathy, do not adequately communicate the potential spectrum of severity of this disorder to affected or carrier family members.

Eye (2006) 20, 234-241. doi:10.1038/sj.eye.6701840; published onilne 18 March 2005

Keywords: Norrin protien; Norrie; NDP; FEVR; FZD4; vitreoretinopathy

\section{Introduction}

The Norrie disease protein (NDP, norrin) is a three-exon gene, which was identified in 1992. ${ }^{1-3}$ The gene encompasses approximately $28 \mathrm{~kb}$ and is located at Xp11.4 (OMIM 310600). The first exon is untranslated, and the protein product is 133 amino acids in length. The protein is a member of the cystine knot growth factor family and it shares a strong similarity to transforming growth factor $\beta .{ }^{4}$ The cystine residues are believed to be critical in the function of these proteins. ${ }^{4}$

It also contains domains with homology to mucins and von Willebrand factor. ${ }^{4}$ Recent evaluation of the mouse homolog suggests that NDP and the frizzled-4 receptor may represent a high-affinity ligand-receptor pair, involved in vascular directional targeting in development. ${ }^{5}$ In addition, NDP has been implicated in the regression of hyaloid vasculature. ${ }^{5,6}$ Mutations in NDP are associated with a wide spectrum of disease severity. The prototypical Norrie disease patient is congenitally blind with bilateral traction retinal detachments or 'pseudogliomas'. ${ }^{7}$ Following the cloning of 
NDP, patients affected with another clinical disorder, $\mathrm{X}$ linked familial exudative vitreoretinopathy (X-linked FEVR, FEVRX, or EVRX), were also found to have mutations in the NDP gene. The phenotype of ' $X$-linked FEVR' is milder than the nine bilaterally blind males reported by Gordon Norrie, ${ }^{8}$ and consists of peripheral retinal pigment epithelial (RPE) changes, an avascular peripheral retina, and a predisposition for retinal detachment. $^{9}$

Familial exudative vitreoretinopathy (FEVR, EVR1) was originally described by Criswick and Schepens. ${ }^{10}$ An autosomal dominant inheritance was ascribed to this disorder by Laqua in 1980 based upon a large German pedigree. ${ }^{11}$ Subsequent reports elaborated on the phenotypic variety among affected family members with autosomal dominant FEVR. ${ }^{12}$ In 1992, a phenotypically similar, X-linked disorder was reported. ${ }^{13}$ The predominant phenotype of autosomal dominant FEVR is characterized by peripheral retinal dysgenesis, retinal traction, peripheral vitreoretinal pigmentary and vascular abnormalities, and subretinal and intraretinal exudates. The disease-causing mutations in the majority of reported families with FEVR maps to 11q13-q23 (OMIM \#133780), although there are some wellcharacterized families that have been excluded from this locus. ${ }^{14,15}$ The preponderance of FEVR that has been molecularly characterized is associated with mutations of the frizzled-4 gene (FZD4) ${ }^{16}$ which encodes a putative Wnt receptor. ${ }^{17,18}$ Recently, mutations in a second gene within the 11q13-q23 interval, low-density-lipoprotien receptor-related protein 5 (LRP5), have also been shown to be associated with clinical cases of FEVR. ${ }^{19}$ LRP5 is a Wnt coreceptor. ${ }^{19}$ Mutant Wnt receptors are involved in altered subcellular trafficking, by oligomerization of mutated FZD4 with wild-type FZD4, trapping the secreted proteins in the endoplasmic reticulum. ${ }^{20}$ At the tissue level, members of the Wnt protein family are known to have a pivotal role in various cellular processes including determination of cell fate, control of cellular polarity, and malignant transformation. ${ }^{18} \mathrm{Wnt}$ receptors or their ligands are implicated in the vascularization of the yolk sac and placenta of mice, ${ }^{21,22}$ and in the osteoporosis-pseudoglioma syndrome (OMIM \#259770), in which there is a developmental failure of the primary vitreous vasculature. $^{23}$

A review of the English language literature produced 11 references to FEVR ${ }^{11,17,18,24-31}$ that collectively reported 42 families whose linkage data were consistent with a disease-causing gene at the FZD4 locus. Of these, 25 families demonstrated pedigree structures that were significantly more consistent with autosomal dominant transmission than $\mathrm{X}$-linked recessive transmission. Within these 25 families, 216 family members were affected and seven were blind at birth.
Although some patients with heterozygous ${ }^{32-34}$ or hemizygous variations in the NDP gene have a phenotype that is indistinguishable from some patients with FEVR, the use of the term X-linked FEVR should be reserved for disorders not associated with NDP mutations. The relationship between genotype and clinical diagnosis becomes even less predictable when one considers that germ line mutations in NDP have been implicated in advanced retinopathy of prematurity (ROP), and somatic mutations have been found in Coats' disease. ${ }^{35,36}$ This imprecision in our clinical nomenclature is of more than academic importance. Female carriers of NDP mutations have a significant risk of giving birth to a bilaterally blind child while the literature would suggest that this eventuality would be extremely uncommon (eg $7 / 216$, see above) for a woman affected with FEVR, or Coats' disease. The use of the term 'FEVR', not otherwise specified, tends to minimize this potentially large difference in outcome in the mind of the patient, their family members, and their doctors.

In this paper, we report a large family with a history of peripheral retinal vascular abnormalities, anterior segment aberrations, and a predisposition towards retinal detachment. A novel mutation in the NDP was found in nine hemizygous individuals of this family. Since this novel mutation represents the most carboxy located mutation reported, an additional unreported family has been included, of a previously reported mutation, Arg74Cys, that further illustrates the phenotypic heterogeneity of Norrie disease.

\section{Methods}

\section{Subjects}

Members of one pedigrees (Figure 1) were examined at The University of Iowa Hospital and Clinics Department of Ophthalmology and Visual Sciences and gave consent to participate in the study. Seven family members of a second NDP family (Figure 2) were identified through a collaboration established during a Project Orbis Training Program in Damascus, Syria from 12 September, 1998 to 3 October, 1998. The University of Iowa Human Subjects Committee approved the study, and all participants signed informed-consent forms prior to participation. Blood samples were collected from 42 family members of pedigree 1 and 7 family members of pedigree 2, and DNA was extracted using standard procedures.

\section{DNA analysis}

Single-strand conformational polymorphism (SSCP) analysis across NDP was performed as previously 
a

I.

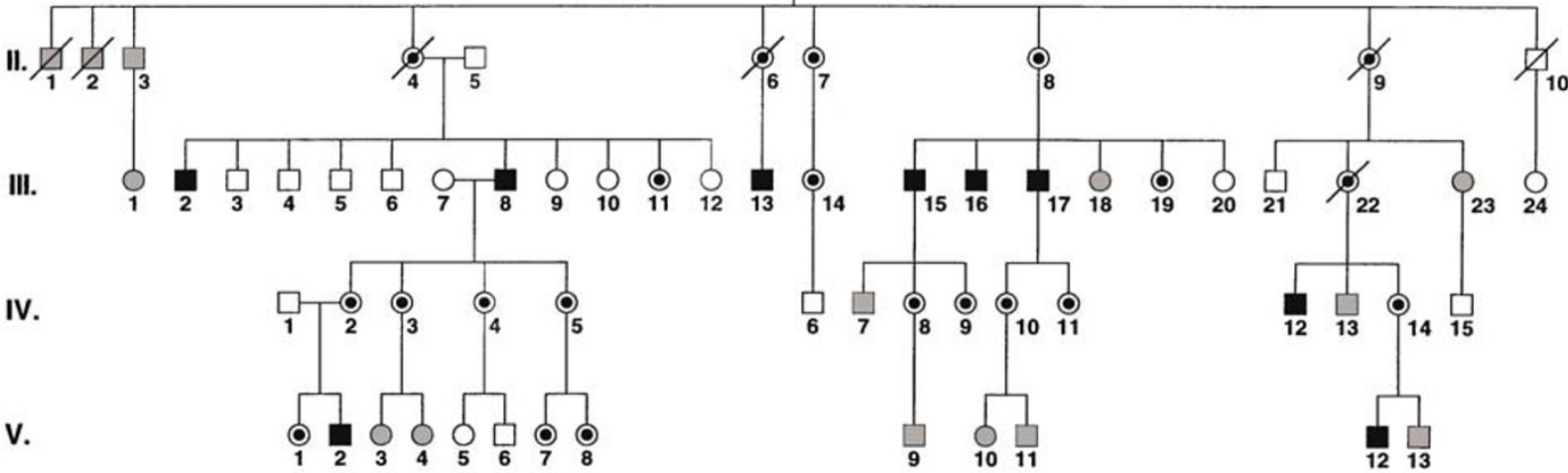

b
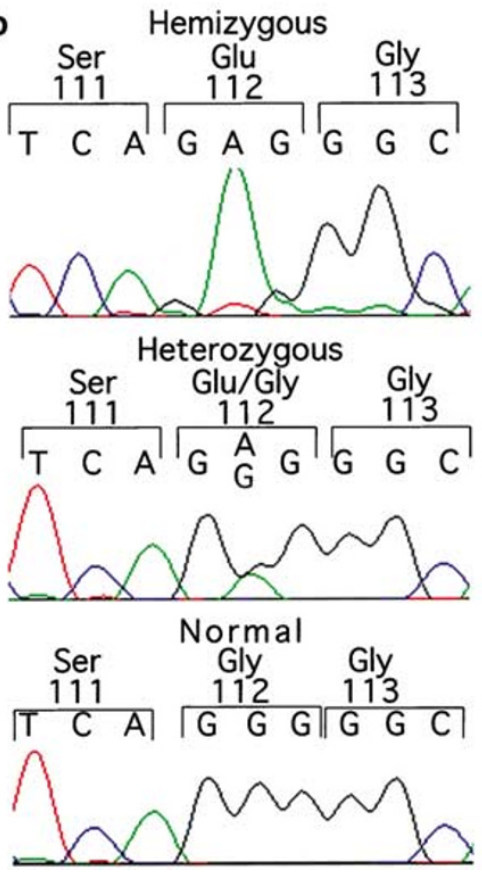

c

e
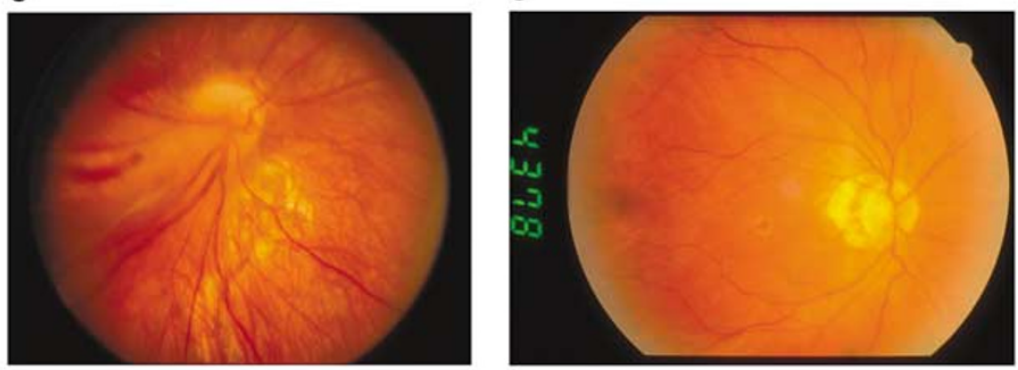

d

$\mathbf{f}$
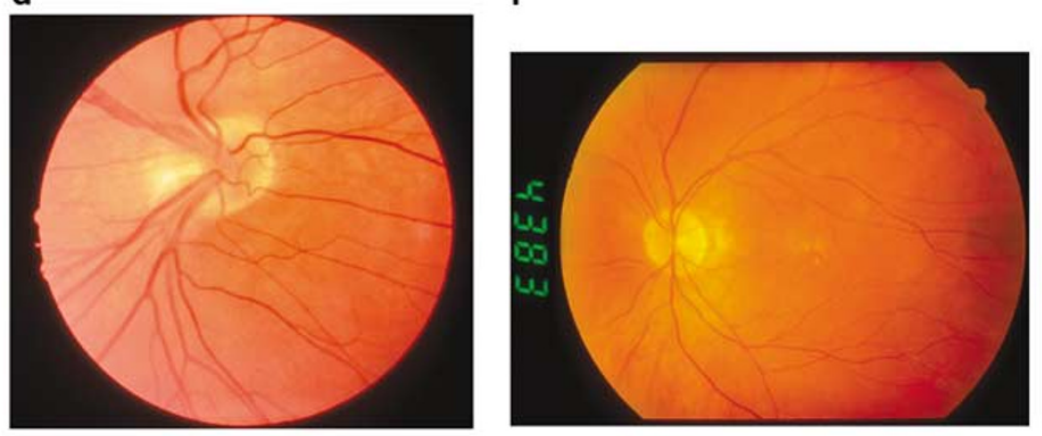

Figure 1 (a) Pedigree 1 of the family affected by a novel Gly112Glu NDP mutation. Pedigree symbol legend: $\square, \bigcirc$, unaffected subjects; $\odot$ known or obligate carrier; $\mathbf{\square}$, affected subject; $\square, O$, unknown status. (b) Direct sequencing of the NDP in hemizygous and heterozygous individuals in Pedigree 1 for a $G$ to A change at nucleotide 743, resulting in a glycine to glutamic acid changes at codon 112. Normal individual is also shown. (c) Fundus photograph of the right eye of patient IV-17, Pedigree 1 in 1963 . Note the presence of a retinal fold and tractional retinal detachment. This phenotype illustrates the similarity in appearance to autosomal dominant familial exudative vitreoretinopathy. (d) Fundus photograph of the right eye from patient V-12, Pedigree 1. (e, f) Fundus photographs of the right (e) and left (f) posterior poles of patient III-8, Pedigree 1. Note the mild degree of annular retinal pigment atrophy in both eyes.

described. ${ }^{2}$ Polyacrylamide gel electrophoresis and silver staining of PCR products were performed as previously described. ${ }^{37}$ The PCR product was purified using Qiagen purification columns as recommended by the manufacturers; $2 \mu \mathrm{l}$ of purified product was used as a template with each of the primers noted above ${ }^{2}$ for sequencing on a $373 \mathrm{ABI}$ automated sequencer. SSCP analysis was also performed on 96 unrelated individuals from the state of Iowa who had been examined and judged to be normal.

\section{Results}

\section{Pedigree 1 (Gly112Glu)}

A large family residing in Iowa was identified, in which a number of males had a history of retinal detachment, anterior segment abnormalities, and peripheral retinal vascular abnormalities (Figure 1). As a result of the Xlinked pattern of inheritance, the NDP was judged to be a good candidate for mutation analysis. SSCP analysis showed an altered migration in the PCR product from 
a

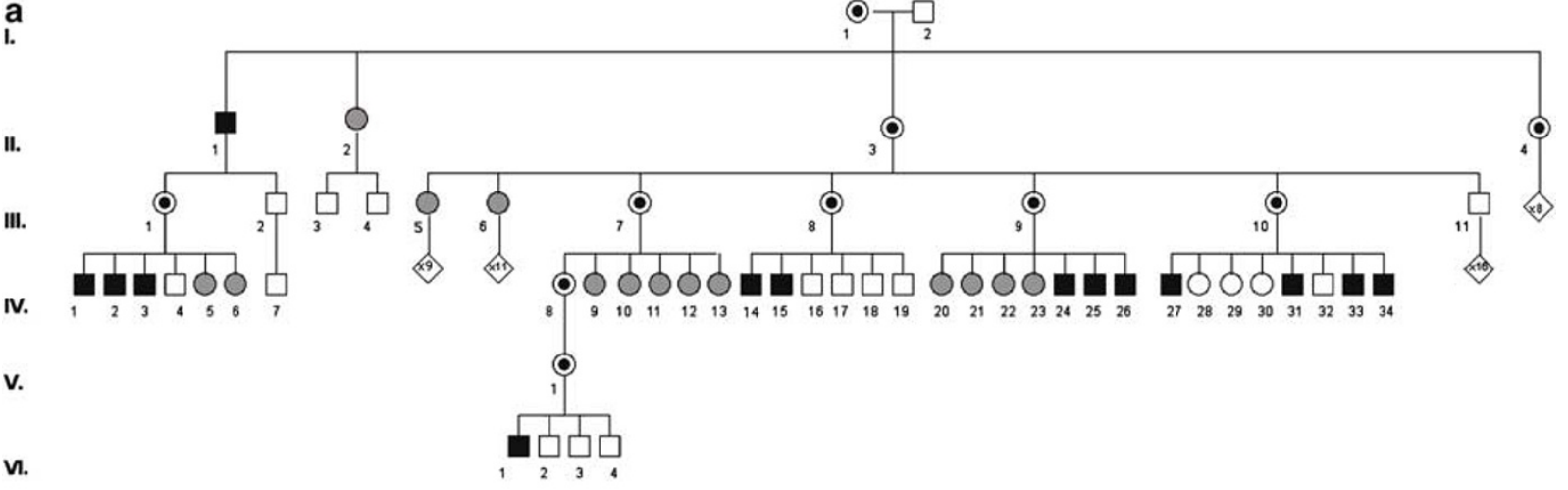

b

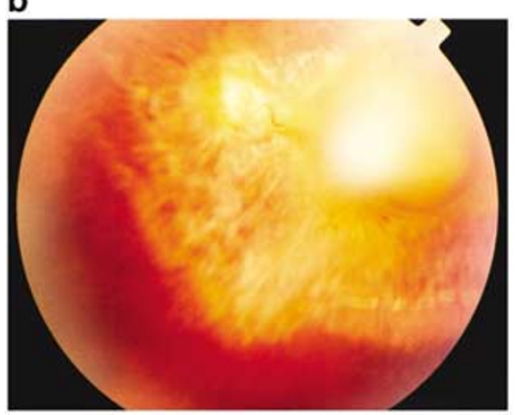

c

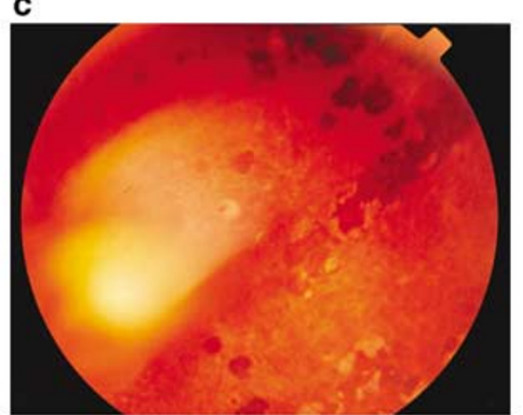

d

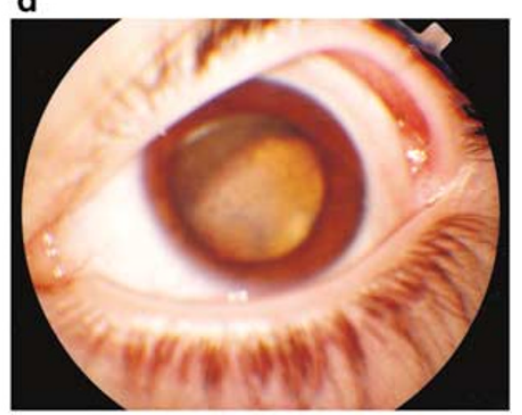

Figure 2 (a) Pedigree of a Syrian family with Arg74Cys NDP mutation. The members molecularly examined for NDP mutations include III-10, and IV-27 to IV-33. Within this branch of the pedigree, four family members were born bilaterally blind. Pedigree symbol legend: $\square, \bigcirc$, unaffected subjects; $\odot$, known or obligate carrier; $\mathbf{\square}$, affected subject; $\square$, $O$, unknown status; $\diamond$, unknown gender, number within the diamond indicates sibling count, when known. (b, c) Patient IV-31 of the Syrian pedigree demonstrates the ' $X$ linked FEVR' phenotype of Norrie disease in the left eye. The eye demonstrates vascular and retinal pigmentary abnormalities and a central fibrotic vitreous membrane, likely derived from dysgenesis of the central vitreous vessels or their degradation. (d) Patient IV-33 of the Syrian pedigree illustrates the 'pseudoglioma' or the prototypic, severe presentation of Norrie disease. Retrolenticular masses consistent with closed-funnel retinal detachments were present in both eyes as depicted by the external view of the left eye.

exon 3 of NDP (data not shown) in 21 family members: nine hemizygous males and 12 heterozygous females. Two of these heterozygotes were examined and both had normal retinal exams. Direct sequencing of this PCR product showed a $\mathrm{G}$ to A change at nucleotide 743, resulting in a glycine to glutamic acid change at codon 112 (Figure 1b). This substitution results in an amino-acid charge change from neutral to acidic within two residues of a highly conserved cystine. No other aberration was noted in the NDP gene. SSCP analysis on 96 unrelated individuals from the State of Iowa showed no identical shift in exon 3 from NDP (data not shown).

Clinical evaluation of the hemizygous individuals demonstrated wide phenotypic differences (Table 1, Figure 1). The proband presented at the age of 3 years with a subtotal retinal detachment of the right eye and an avascular peripheral retina and at the age of 4 years, he developed a macula-off tractional retinal detachment of the left eye. The proband's maternal grandfather, at age 79 years old, had a normal eye exam except for mild, fine peripheral RPE clumping. The remaining seven hemizygous family members had varying degrees of anterior segment and peripheral retinal abnormalities. No individual had a history of prematurity or low birth weight. The mean age of affected family members at evaluation was 39 years (range 3-78 years). Six of nine $(67 \%)$ family members had a visual acuity of counting fingers or worse in one eye. The mean visual acuity in the better eye of all nine hemizygotes was 20/30. A retinal detachment occurred in six of 18 eyes (33\%). Seven of 18 eyes $(39 \%)$ had an avascular peripheral retina and four $(22 \%)$ had temporal dragging of the retinal vessel. Two individuals (11\%) had only central and peripheral RPE changes. In the anterior segment, two eyes (11\%) had a white cataract, and three eyes $(17 \%)$ had a posterior subcapsular cataract.

\section{Pedigree 2 (Arg74Cys)}

Pedigree 2 represents a large family residing in and around Damascus, Syria. Three young siblings were initially examined and demonstrated a phenotypic distribution from moderately affected (subject IV-31, see Figure $2 \mathrm{~b}$ and $\mathrm{c}$; ' $\mathrm{X}$-linked FEVR') to prototypic Norrie 
Table 1 Representative kin with Gly112Glu in NDP

\begin{tabular}{|c|c|c|c|c|c|c|c|c|c|}
\hline \multirow[t]{2}{*}{ Patient } & \multirow{2}{*}{$\begin{array}{l}\text { Age } \\
\text { (years) }\end{array}$} & \multirow{2}{*}{$\begin{array}{l}\text { Years of } \\
\text { follow-up }\end{array}$} & \multicolumn{2}{|c|}{ Vision } & \multirow[t]{2}{*}{ Initial refractive error } & \multicolumn{2}{|c|}{ Slit-lamp examination } & \multicolumn{2}{|c|}{ Fundus examination } \\
\hline & & & Right eye & Left eye & & Right eye & Left eye & Right eye & Left eye \\
\hline $\mathrm{V}-2$ & 6 & 3 & Light perception & $20 / 60$ & +0.75 sphere OS & Normal & Normal & $\begin{array}{l}\text { Avascular periphery } \\
\text { Total retinal detachment }\end{array}$ & $\begin{array}{l}\text { Avascular periphery } \\
\text { Retinal detachment }\end{array}$ \\
\hline III-15 & 65 & 17 & Hand motions & $20 / 40$ & -3.75 sphere OS & $\begin{array}{l}\text { White } \\
\text { cataract }\end{array}$ & $\begin{array}{l}\text { Posterior subcap-sular } \\
\text { cataract }\end{array}$ & Congenital retinal fold & $\begin{array}{l}\text { Temporal dragging of } \\
\text { vessels } \\
\text { Avascular periphery } \\
\text { Retinal detachment }\end{array}$ \\
\hline III-16 & 61 & 4 & $20 / 25$ & $20 / 160$ & -8.50 sphere OD & $\begin{array}{l}\text { Posterior } \\
\text { subcap-sular } \\
\text { cataract }\end{array}$ & Brunescent cataract & $\begin{array}{l}\text { Peripheral pigmentary } \\
\text { changes }\end{array}$ & $\begin{array}{l}\text { Peripheral pigmentary } \\
\text { changes }\end{array}$ \\
\hline III-17 & 53 & 47 & Light perception & $20 / 30$ & $\begin{array}{l}-6.75 \text { sphere OD } \\
-8.75 \text { sphere OS }\end{array}$ & Normal & Normal & $\begin{array}{l}\text { Congenital retinal fold } \\
\text { Retinal detachment }\end{array}$ & Normal \\
\hline III-13 & 62 & 15 & $20 / 50$ & $\begin{array}{l}\text { Count } \\
\text { fingers }\end{array}$ & $\begin{array}{l}-2.00 \text { sphere OD/ } \\
\text { OS }\end{array}$ & Normal & $\begin{array}{l}\text { Posterior subcap-sular } \\
\text { cataract }\end{array}$ & $\begin{array}{l}\text { Avascular peripheral } \\
\text { retina } \\
\text { Peripheral fibrotic ridge } \\
\text { Temporal dragging of } \\
\text { vessels }\end{array}$ & $\begin{array}{l}\text { Avascular peripheral } \\
\text { retina } \\
\text { Peripheral fibrotic ridge } \\
\text { Macular dystopia }\end{array}$ \\
\hline IV-12 & 53 & 39 & Enucleation & $20 / 20$ & +5.00 sphere OS & Enucleation & Normal & Retinal detachment & $\begin{array}{l}\text { Temporal dragging of } \\
\text { vessels }\end{array}$ \\
\hline $\mathrm{V}-12$ & 33 & 20 & $20 / 20$ & $\begin{array}{l}\text { No light } \\
\text { perception }\end{array}$ & + 1.00 sphere OD & Normal & White cataract & $\begin{array}{l}\text { Temporal dragging } \\
\text { of vessels } \\
\text { Abnormal vessels }\end{array}$ & Retinal detachment \\
\hline III-8 & 79 & 1 & $20 / 30$ & $20 / 30$ & $\begin{array}{l}+1.00 \text { sphere } \\
\text { OD/OS }\end{array}$ & $\begin{array}{l}2+\text { nuclear } \\
\text { sclerosis }\end{array}$ & $\begin{array}{l}2+\text { nuclear } \\
\text { sclerosis }\end{array}$ & $\begin{array}{l}\text { Mild peripheral and } \\
\text { central retinal pigment } \\
\text { epithelial changes }\end{array}$ & $\begin{array}{l}\text { Mild peripheral and } \\
\text { central retinal pigment } \\
\text { epithelial changes }\end{array}$ \\
\hline
\end{tabular}


disease (subject IV-33, see Figure 2d, 'pseudoglioma' from birth). Depending on the designation of the proband, this disorder might be characterized as either 'Norrie disease' or 'X-linked FEVR'. Mutation analysis demonstrated that a previously reported NDP mutation, Arg74Cys, segregated with clinically affected males. One female sibling was shown to have haploinsufficiency but did not demonstrate any retinal or acoustic abnormalities.

\section{Illustrative members, Pedigree 1 (Gly112Glu)}

\section{Subject $V-2$}

The proband is a 6-year-old male, who initially presented in 1997 when the parents noted that the right eye 'wandered' and, on further evaluation, found that the patient did not see well from the right eye. Previous medical and birth history were unremarkable. On evaluation, vision was light perception, right eye, and $20 / 25$, left eye. Fundus examination revealed a maculaoff, subtotal retinal detachment of the right eye with an avascular peripheral retina. Based on prior outside records, the duration of macular detachment was longstanding. The left fundus showed two areas of elevated telangiectatic vessels and an avascular periphery. In 1998, vision declined to 3/100, left eye. A tractional retinal detachment was found, which involved the macula. A scleral buckle procedure, pars plana vitrectomy, membrane peel, and endolaser were performed. In 1999, the retina remained attached and vision improved to $20 / 60$ in the left eye.

\section{Subject III-15}

The patient is a 65-year-old male, who initially presented in 1983 for evaluation. Patient admitted he had never seen well from his right eye and was diagnosed with a congenital retinal fold with 'mild PHPV' of the right eye. In 1983, a macula-off retinal detachment of the left eye was noted, for which he had an SBP performed. A posterior subcapsular cataract developed of the left eye, and an ECCE was performed with no IOL. YAG capsulotomy was performed in 1985. Persistent CME developed and a pars plana vitrectomy was performed. In 1996, his left retina redetached, and a membrane peeling, endolaser, and gas fluid exchange was performed. On last examination in 1999, his vision was HM, right eye, and 20/40, left eye. The slit-lamp examination showed a white cataract of the right eye and aphakia of the left eye. There was no view of the right fundus; however, ultrasonography demonstrated a tractional macular detachment that extended to the temporal periphery. Owing to the chronicity of the retinal detachment in the right eye, no surgery was recommended. The left fundus showed the retina to be flat with temporal dragging of the vessels and laser scars. The periphery appeared avascular.

\section{Subject III-17}

The patient is a 53-year-old male, who initially presented in 1963 with a congenital retinal fold (Figure 1c) and a complete RD with a giant tear in the right eye. An SBP was performed, followed by a revision. The left fundus was reported as normal. No retinal vascular or pigmentary changes were noted.

\section{Subject $V-12$}

The patient is a 33-year-old male, who had a retinal detachment in the left eye at age 13 years. An SBP was performed; however, the retina remained detached. The patient received peripheral scatter photocoagulation to peripheral abnormal vessels in the right eye. On examination in 1999, vision was 20/20, right eye and NLP, left eye. Fundus examination of the right eye showed a ridge of telangiectatic vessels with temporal dragging of the retinal vessels (Figure 1d). There was no view of the left fundus; echography showed a total retinal detachment.

\section{Subject III-8}

This family member is a 78-year-old male who had no visual complaint. In 1999, the visual acuity was 20/30, right eye and 20/30, left eye. A slit-lamp examination showed moderate nuclear sclerotic cataracts with cortical changes. Fundus examination demonstrated peripheral and central pigmentary changes with no temporal dragging of the vessels and no areas of avascular retina (Figure 1e and $\mathrm{f}$ ).

\section{Discussion}

Phenotypic variation associated with different mutations in the NDP has previously been reviewed. ${ }^{38,39}$ Overall, there is a rough genotype-phenotype correlation: missense mutations affecting amino acids near the carboxy-terminus of the protein seem to result in a less severe form of disease, often manifested as an exudative peripheral vitreoretinopathy. In this communication, we report a mutation in NDP that has not been previously described. It is characterized by significant intra-familial phenotypic variability. This class of expression has some interesting implications with respect to genetic counselling in families found to have a mutation in NDP. We believe that NDP-associated disease should be called 'Norrie disease' and that clinicians should be aware that the range of expressivity ranges from blindness at birth to subtle ophthalmoscopic vision with normal visual acuity. By using the term 'Norrie disease', family members will not be given a false sense of security that 
they have a 'mild disease' with a small chance of serious complications in their children. Moreover, children of females with NDP gene variations will be more likely to receive early retinal exams and preventative treatment, if indicated. Now that genetic testing for Norrie disease is available at a reasonable cost, clinicians are in a position to make a precise (genetic) diagnosis by considering ophthalmoscopy, pedigree analysis, and when needed, molecular testing of the NDP gene (www.genetests.org, www.carverlab.org).

The Syrian pedigree illustrates the dilemma of utilizing the term ' $X$-linked FEVR' to refer to families or individuals with NDP disease. If subject IV-33 was designated as the proband, the disorder might be called 'X-linked FEVR', whereas, if subject IV-31 were designated as the proband, Norrie disease would be used. We believe that when the genetic basis of the disorder is known, the designation of the diagnosis should be unequivocal.

Considerable range of expression among affected family members has been demonstrated for a number of NDP mutations. Explanation for the individual variability may be related to the function of NDP. Currently, NDP is thought to function in the differentiation or maintenance of the differentiated state of the retina through cell adhesion and neurodevelopment. ${ }^{40}$ In situ hybridization has shown expression of the NDP mRNA in the outer nuclear, inner nuclear and ganglion cell layer of the retina. ${ }^{40}$ Owing to this extensive range of expression of the gene and its role in differentiation, NDP may interact with additional genes. Mutations such as the one that is reported in this family might allow such modifying genes to be identified in the future by employing a candidate gene approach to screen genes that are known to be mechanistically linked to the NDP gene.

\section{Acknowledgements}

Presented in part at the Association for Research in Vision and Ophthalmology (ARVO) in Ft. Lauderdale, Florida on April 30, 2000. Supported by an unrestricted grant from Research to Prevent Blindness (New York, NY) to the Department of Ophthalmology and Visual Sciences, The University of Iowa Carver School of Medicine, The Carver Endowment to Molecular Ophthalmology, National Institutes of Health (EMS) and the Howard Hughes Medical Institute (EMS). Proprietary interest: None.

\section{References}

1 Berger W, Meindl A, van de Pol T, Cremers F, Ropers H, Doerner $\mathrm{C}$ et al. Isolation of a candidate gene for Norrie disease by positional cloning. Nat Genet 1992; 1: 199-203.
2 Chen Z-Y, Hendriks R, Jobling M, Powell J, Breakefield X, Sims $\mathrm{K}$ et al. Isolation and characterization of a candidate gene for Norrie disease. Nat Genet 1992; 1: 204-208.

3 Meindl A, Berger W, Meitinger T, van de Pol D, Achatz H, Dorner $\mathrm{C}$ et al. Norrie disease is caused by mutation in an extracellular protein resembling C-terminal globular domain of mucins. Nat Genet 1992; 2: 139-143.

4 Meitinger T, Meindl A, Bork P, Rost B, Sander C, Haasemann $\mathrm{M}$ et al. Molecular modeling of the Norrie disease protein predicts a cystine knot growth factor tertiary structure. Nat Genet 1993; 5: 376-380.

5 Xu Q, Wang Y, Dabdoub A, Smallwood PM, Williams J, Woods $\mathrm{C}$ et al. Vascular development in the retina and inner ear: control by norrin and frizzled-4, a high-affinity ligandreceptor pair. Cell 2004; 116: 883-895.

6 Ohlmann AV, Adamek E, Ohlmann A, Lutjen-Driscoll E. Norrie gene product is necessary for regression of hyaloid vessels. Invest Ophthalmol Vis Sci 2004; 45: 2384-2390.

7 Warburg M. Norrie's disease: a new hereditary bilateral pseudotumor of the retina. Acta Ophthal (Copenhagen) 1961; 39: 757-772.

8 Norrie G. Causes of blindness in children: twenty-five years' experience of Danish Instututes for the Blind. Acta Ophthal (Copenhagen) 1927; 5: 357-386.

9 Chen Z-Y, Battinelli E, Fielder A, Bundey S, Sims K, Breakefield $X$ et al. A mutation in the Norrie disease gene (NDP) associated with X-linked familial exudative vitreoretinopathy. Nat Genet 1993; 5: 180-183.

10 Criswick V, Schepens C. Familial exudative vitreoretinopathy. Am J Ophthal 1969; 68: 578-594.

11 Laqua H. Familial exudative vitreoretinopathy. Albrecht Graefes Arch Klin Exp Ophthalmol 1980; 213: 121-133.

12 Jacklin H. Falciform fold, retinal detachment, and Norrie's disease. Am J Ophthalmol 1980; 90: 76-80.

13 Plager D, Orgel I, Ellis F, Hartzer M, Trese M, Shastry B. Xlinked recessive familial exudative vitreoretinopathy. Am J Ophthalmol 1992; 114: 145-148.

14 Toomes C, Downey LM, Bottomley HM, Scott S, Woodruff $\mathrm{G}$, Trembath RC et al. Identification of a fourth locus (EVR4) for familial exudative vitreoretinopathy (FEVR). Mol Vis 2004; 10: 37-42.

15 Downey LM, Keen T, Roberts E, Mansfield D, Basmashmus $\mathrm{M}$, Inglehearn CF. A new locus for autosomal dominant familial exudative vitreoretinopathy maps to chromosome 11p12-13. Am J Hum Genet 2001; 68: 778-781.

16 Toomes C, Bottomley HM, Scott S, Mackey DA, Craig JE, Appukuttan B et al. Spectrum and frequency of FZD4 mutations in familial exudative vitreoretinopathy. Invest Ophthalmol Vis Sci 2004; 45: 2083-2090.

17 Kondo H, Hayashi H, Oshima K, Tahira T, Hayashi K. Frizzled 4 gene (FZD4) mutations in patients with familial exudative vitreoretinopathy. Br J Ophthalmol 2003; 87: 12911295.

18 Robitaille J, MacDonald MLE, Kaykas A, Sheldahl LC, Zeisler J, Dube M-P et al. Mutant frizzled-4 disrupts retinal angiogenesis in familial exudative vitreoretinopathy. Nature Genet 2002; 32: 326-330.

19 Toomes C, Bottomley HM, Jackson RM, Towns KV, Scott S, Mackey DA et al. Mutations in LRP5 or FZD4 underlie the common familial exudative vitreoretinopathy locus on chormosome 11q. Am J Hum Genet 2004; 74: 721-730.

20 Kaykas A, Yang-Snyder J, Heroux M, Shah K, Bouvier M, Moon RT. Mutant frizzled 4 associated with vitreoretinopathy traps wild-type frizzled in the 
endoplasmic reticulum by oligomerization. Nat Cell Biol 2004; 6: 52-58.

21 Ishikawa T, Tamai Y, Zorn AM, Yoshida H, Seldin MF, Nishikawa $S$ et al. Mouse Wnt receptor gene Fzd5 is essential for yolk sac and placental angiogenesis. Development 2001; 128: 25-33.

22 Monkley S, Delaney S, Pennisi D, Christiansen J, Wainwright B. Targeted disruption of the Wnt2 gene results in placentation defects. Development 1996; 122: 3343-3353.

23 Gong Y, Slee RB, Fukai N, Rawadi G, Roman-Roman S, Reginato AM et al. LDL receptor-related protein 5 (LRP5) affects bone accrual and eye development. Cell 2001; 107: 513-523.

24 Li Y, Muller B, Furhmann C, van Nouhuys CE, Laqua H, Humphries $\mathrm{P}$ et al. The autosomal dominant familial exudative vitreoretinopathy locus maps to $11 \mathrm{q}$ and is closely linked to D11S533. Am J Hum Genet 1992; 51: 749-754.

25 van Nouhuys CE. Dominant exudative vitreoretinopathy and other vascular developmental disorders of the peripheral retina. In: Bagolini B, von Bahr G, Blodi FC, Francois J, Friedmann AJ, Goldmann $\mathrm{H}$ et al. (eds) Documenta Ophthalmologica. W. Junk: The Hague, 1982, p 414.

26 Kondo H, Ohno K, Tahira T, Hayashi H, Oshima K, Hayashi $\mathrm{K}$. Delineation of the critical interval for the familial exudative vitreoretinopathy by linkage and haplotype analysis. Hum Genet 2001; 108: 368-375.

27 Price S, Perian N, Humphries A, Woodruff G, Trembath R. Familial exudative vitreoretinopathy linked to D11S522 in a large Asian family with consanguinity. Ophthalmic Genet 1966; 17: 53-57.

28 Gow J, Oliver G. Familial exudative vitreoretinopathy. Arch Ophthalmol 1971; 86: 150-155.

29 Feldman E, Norris J, Cleasby G. Autosomal dominant exudative vitreoretinopathy. Arch Ophthalmol 1983; 101: 1532-1535.
30 Nicholson D, Galvis V. Criswick-Schepens syndrome (familial exudative vitreoretinopathy): study of a Columbian kindred. Arch Ophthalmol 1984; 102: 1519-1522.

31 Miyakubo H, Inohara N, Hashimoto K. Retinal involvement in familial exudative vitreoretinopathy. Ophthalmologica 1982; 185: 125-135.

32 Shastry B, Hiraoka M, Trese D, Trese M. Norrie disease and exudative vitreoretinopathy in families with affected female carriers. Eur J Ophthalmol 1999; 9: 238-242.

33 Sims K, Irvine A, Good W. Norrie disease in a family with a manifesting female carrier. Arch Ophthalmol 1997; 115: 517-519.

34 Meire F, Lafaut B, Speleman F, Hanssens M. Isolated Norrie disease in a female caused by a balanced translocation $\mathrm{t}(\mathrm{X}, 6)$. Ophthalmic Genet 1998; 19: 203-207.

35 Shastry BS, Pendergast SD, Hartzer MK, Liu X, Trese M. Identification of missense mutation in the Norrie disease gene associated with advanced retinopathy of prematurity. Arch Ophthalmol 1997; 115: 651-655.

36 Black G, Perveen R, Bonshek R, Cahill M, Clayton-Smith J, Lloyd IC et al. Coats' disease of the retina (unilateral retinal telangiectasis) caused by somatic mutation in the NDP gene: a role for norrin in retinal angiogenesis. Hum Mol Genet 1999; 8: 2031-2035.

37 Nichols BE, Bascom R, Litt M, McInnes R, Sheffield VC, Stone EM. Refining the locus for Best's vitelliform macular dystrophy and mutation analysis of the candidate gene ROM1. Am J Hum Genet 1994; 54: 95-103.

38 Kellner U, Fuchs S, Bornfeld N, Foerster M, Gal A. Ocular phenotypes associated with two mutations (R121W, C126X) in the Norrie disease protein. Ophthalmic Genet 1996; 17: 67-74.

39 Berger W. Molecular dissection of Norrie disease. Acta Anat 1998; 162: 95-100.

40 Hartzer M, Cheng M, Liu X, Shastry B. Localization of the Norrie disease gene by mRNA in situ hybridization. Brain Res Bull 1999; 49: 355-358. 